Artigo

\title{
Linguagem matemática, ensino de Geometria e língua materna: saberes docentes de uma professora formadora em um curso de Pedagogia
}

\author{
Mathematical language, Geometry teaching and mother tongue: teaching knowledge of a \\ teacher educator in a Pedagogy degree course
}
Lenguaje matemático, enseñanza de Geometría y lengua materna: saberes docentes de una profesora formadora en una carrera de Pedagogía

\author{
Pedro Augusto Mazini dos Santos ${ }^{1}$ \\ [0000-0002-3552-3229] \\ Marcelo Carlos de Proença ${ }^{2}$ \\ [0000-0002-6496-4912]
}

\begin{abstract}
Resumo
No presente artigo, apresentamos o recorte de uma pesquisa de mestrado cujo objetivo foi o de investigar que elementos dos saberes docentes são colocados em ação na prática pedagógica quando o professor formador articula linguagem matemática e língua materna no ensino de Geometria em uma disciplina de Metodologia de Ensino de Matemática em um curso de Pedagogia. Para tanto, como opção metodológica, realizamos uma pesquisa qualitativa do tipo estudo de caso, com uma professora formadora, em uma universidade pública, localizada no Estado do Paraná. Analisamos os dados, organizando-os na forma de episódios. Para este artigo, trazemos um dos episódios analisados, no qual, a professora formadora defende o ensino de Geometria por meio de atividades práticas e materiais manipuláveis. Os resultados mostraram que a professora formadora apresentou às futuras pedagogas possibilidades com materiais manipuláveis para o ensino de geometria, revelando uso de saber profissional. Todavia, no decorrer da utilização desses materiais, não se aprofundou nos conteúdos que poderiam ser ministrados em sala de aula. Diante disso, não percebemos em sua prática a articulação entre linguagem geométrica e a língua materna que pudesse promover a formação das futuras pedagogas. Concluímos que é necessário haver aprofundamento dos saberes disciplinares, ligados aos conhecimentos geométricos a serem ensinados nos anos iniciais para que se tenha oportunidades de estabelecer uma articulação entre linguagem matemática e língua materna.
\end{abstract}

Palavras-chave: Materiais manipuláveis. Linguagem geométrica. Professor formador.

\begin{abstract}
This article is a part of a master's research wich aimed to examine what elements of the teaching knowledge are put into action in the pedagogical practice when a teacher educator articulates mathematical language and mother tongue in the geometry teaching into a discipline of Mathematics Teaching Methodology in a Pedagogy degree course. In order to achieve its purpose, the research was methodologicaly leaded as a qualitative research developed as a case study, with a teacher educator, in a public university, located in the State of Paraná. The data were organized in episodes with the view to be analized and, in this paper, one of them is showed, one in which the professor defends the Geometry teaching through practical activities and manipulable materials. The results showed that the professor presented to their students, prospective teachers, possibilities with manipulable materials

${ }^{1}$ pedro.mbmazini@gmail.com, Mestre, Bolsista, Universidade Estadual de Maringá, Maringá/PR/Brasil.

2 mcproenca@uem.br, Doutor, Professor, Universidade Estadual de Maringá, Maringá/PR/Brasil.
\end{abstract}


for teaching geometry, revealing the use of professional knowledge. Despite of it, even taking these materials, the professor did not develop deeply the content that could be taught in the classroom. Because of it, we do not realize in the practice analized the articulation between geometric language and the mother tongue that could promote the development of future educators. In this way, we conclude that it is necessary to explore deeply the disciplinary knowledge, linked to geometric knowledge to be taught in the early years, in order to have opportunities to achieve an articulation between mathematical language and mother tongue.

Keywords: Manipulable materials. Geometric language. Teacher educator.

\section{Resumen}

En el presente artículo, presentamos el recorte de una investigación de maestría cuyo objetivo fue el de pesquisar qué elementos de los saberes docentes son puestos en acción en la práctica pedagógica cuando el profesor formador articula lenguaje matemático y lengua materna en la enseñanza de Geometría en una asignatura de Metodología de Enseñanza de Matemáticas en una carrera de Pedagogía. Para esto, como opción metodológica, realizamos una investigación cualitativa del tipo estudio de caso, con una profesora formadora, en una universidad pública, ubicada en el Estado de Paraná. Analizamos los datos, organizándolos en episodios. Para este artículo, traemos uno de los episodios analizados, en el cual, la profesora formadora defiende la enseñanza de Geometría por medio de actividades prácticas y materiales manipulativos. Los resultados nos mostraron que la profesora formadora presentó a las futuras pedagogas posibilidades con materiales manipulativos para la enseñanza de Geometría, revelándonos el uso del saber profesional. Sin embargo, en el transcurrir de la utilización de estos materiales, no se profundizó en los contenidos que podrían ser ministrados en el salón de clase. Ante esto, no percibimos em su práctica la articulación entre lenguaje geométrica y la lengua materna que pudiera promover la formación de futuras pedagogas. Concluimos que es necesario haber profundización de los saberes de las disciplinas, relacionados a los conocimientos geométricos a ser enseñados en los años iniciales para que se tenga oportunidades de establecer una articulación entre lenguaje matemático y lengua materna.

Palabras claves: Materiales manipulativos. Lenguaje geométrico. Profesor formador.

\section{Introdução}

Parece um paradoxo que, em um mundo no qual a Geometria é tão presente tanto como instrumento de informação e representação, por meio de imagens e símbolos, como na compreensão do bidimensional e tridimensional, o ensino de seus conceitos ainda seja tão problemático. Desse modo, consideramos relevante estudar as condições que têm limitado o potencial de ensino desses conceitos por parte dos professores.

Pavanello (1989, 1993, 2004), Pavanello et. al. (1995), Nacarato (2000, 2002), Curi (2004, 2005) contribuíram por mais de duas décadas com o Ensino de Geometria e são pioneiros em pesquisas envolvendo a formação inicial e continuada de Professores Polivalentes $^{3}$ sobre essa temática. Esses autores evidenciam em suas pesquisas o "abandono" do ensino da Geometria e suas consequências, pois o professor que presenciou esse abandono, e não aprendeu Geometria enquanto aluno, potencializará essa relação negativa e se sentirá inseguro para abordar o conteúdo em sala de aula.

Nossa pesquisa busca contribuir com a compreensão deste cenário que retrata o professor que ensina matemática, mais especificamente, no campo da Geometria. Como

\footnotetext{
${ }^{3}$ Seria aquele que atua como professor nos anos iniciais do ensino fundamental, podendo ministrar disciplinas diferentes, embasando, dessa forma, a ideia de formação de professores generalistas.
} 
recorte, propusemos em nosso estudo, investigar uma professora formadora que atua em um curso de Pedagogia, na disciplina de Metodologia de Ensino da Matemática. A atuação do professor formador em cursos de licenciatura tem sido discutida por alguns autores (VASCONCELOS, 1998; PAVANELLO, 2004; CURI, 2005; ALMEIDA, 2009; SANTOS, 2009, DE JESUS, 2015), sendo que apenas as pesquisas de Curi (2005); Almeida (2009) e De Jesus (2015) se dedicaram a compreender a atuação do profissional que forma matematicamente o licenciado em Pedagogia.

No intuito de compreender o cenário de formação do professor que irá ensinar Geometria nos anos iniciais, elencamos como objetivo deste artigo investigar que elementos dos saberes docentes na docência de Geometria para o curso de Pedagogia são colocados em ação na prática pedagógica quando o formador articula Linguagem Matemática e Língua Materna. Entendemos que, em grande parte, é o professor formador que possibilita, segundo Taques Filho (2012), às futuras pedagogas, ter uma formação que lhes permita "refletir sobre suas atitudes, concepções e crenças, percebendo a amplitude do ensino da matemática, tendo a possibilidade de mudar e se reconstruir face aos desafios impostos pela sociedade atual" (TAQUES FILHO, 2012, p. 266).

\section{0 professor formador e os saberes docentes}

Curi (2005) e Almeida (2009) revelam, em seus estudos, que a maioria dos formadores da área de Matemática, no curso de Licenciatura em Pedagogia, tem formação em nível de graduação de Licenciatura Plena em Pedagogia e, em nível de pós-graduação, mestrado e doutorado em Educação. No Brasil, as instituições de ensino superior que oferecem o curso de Pedagogia não determinam como deve ser o perfil da formação acadêmica do professor formador da área de Matemática. Dessa forma, cabe a cada instituição decidir o que é mais conveniente para a formação de seus licenciados em Pedagogia.

Nesse sentido, compartilhamos com Curi (2011) quando a autora diz que:

[...] para ensinar bem, o professor precisa ser um profissional que domine com segurança os conteúdos do ensino e as condições de ensino, o que requer conhecimentos específicos. Pressupõe um conhecimento base e necessita de espaço e condições para a tomada de decisões. O professor deve ser aquele que faz, sabendo como e quando fazer. (CURI, 2011, p. 93).

A fala da autora vai ao encontro das indicações apresentadas nos Parâmetros Curriculares Nacionais de Matemática (PCN), pois o documento afirma que:

[...] para desempenhar seu papel de mediador entre o conhecimento matemático e o aluno, o professor precisa ter um sólido conhecimento dos conceitos e procedimentos dessa área e uma concepção de Matemática como ciência que não trata de verdades infalíveis e imutáveis, mas como ciência dinâmica, sempre aberta à incorporação de novos conhecimentos. (BRASIL, 1998, p. 36).

Tanto a fala de Curi (2005) quanto o trecho do PCN de Matemática estão relacionados com os saberes docentes que o professor precisa mobilizar para ensinar e lidar com as situações cotidianas em sala. Para Tardif (2002), o saber docente é "um saber plural, formado 
pelo amálgama, mais ou menos coerente, de saberes oriundos da formação profissional e de saberes disciplinares, curriculares e experienciais" (TARDIF, 2002, p.36).

Tendo como base as caracterizações desse saber plural necessário à atuação docente, no presente artigo, resgatamos o conceito de cada saber, conforme propôs Tardif (2002):

a) saberes profissionais: os saberes construídos por um profissional inserido em instituições de formação de professores, tais como Magistério, cursos de Pedagogia, Normal Superior e demais licenciaturas;

b) saberes disciplinares: definidos e selecionados pelas universidades, como os saberes de conteúdos específicos de Matemática, Português, História, Geografia e demais áreas do conhecimento e trabalhados ao longo da "formação (inicial e contínua) dos professores nas diversas disciplinas";

c) saberes curriculares: os que "correspondem aos discursos, objetivos, conteúdos e métodos a partir dos quais a instituição escolar categoriza e apresenta os saberes sociais por ela definidos e selecionados", apresentados, nos diversos textos oficiais, sob a forma, por exemplo, de programas escolares;

d) saberes práticos ou experienciais: definidos pelos saberes que emergem da própria experiência do professor frente às situações dinâmicas e inusitadas que ocorrem em sala de aula e são por ela validados (TARDIF, 2002, p.38).

Tendo em vista as caracterizações desse saber plural necessário à atuação docente, no presente trabalho, buscamos fundamentados nas observações da aula de Geometria de uma professora formadora identificar esses saberes docentes ao articular linguagem matemática e língua materna em sua prática pedagógica.

\section{A linguagem matemática nas aulas de Geometria}

Diferentes pesquisas (KALEFF, 1994; PAVANELLO et. al. 1995; CURI, 2004; VASCONCELLOS, 2008; FURLANETTO, 2013; SCHIRLO; RUTZ DA SILVA, 2013; MORETTI, 2018; ZORTÊA, 2018) indicam em seus resultados que professores formados em Pedagogia apresentam lacunas conceituais referentes ao conhecimento matemático em todos os eixos do currículo, tais como: Números e Operações; Pensamento Algébrico; Espaço e Forma/Geometria; Grandezas e Medidas e Tratamento da Informação/Estatística e Probabilidade. Para esses pesquisadores, o campo mais fragilizado é o da Geometria.

Essa ausência de conhecimento da Geometria, segundo Vasconcellos (2008), faz com que os professores dos anos iniciais do Ensino Fundamental resistam à ideia de abordar esse conteúdo em suas aulas. Consequentemente, como resultado de sua pesquisa, a autora afirma que os alunos, mesmo após terem cursado os anos iniciais do Ensino Fundamental, e, possivelmente, terem vivenciado "situações relacionadas, por exemplo, às figuras não planas e planas, continuavam confundindo seus nomes, chamando, o cubo de quadrado, o paralelepípedo de retângulo, bem como não reconhecendo as mesmas figuras em diferentes posições". (VASCONCELLOS, 2008, p. 78).

Vasconcellos (2008) complementa, ainda, que a ausência do conhecimento Linguagem Geométrica por parte do professor, compromete o desenvolvimento dos alunos, pois percebe-se que, devido a sua dificuldade com o uso da linguagem, há uma priorização apenas no trabalho com figuras geométricas planas e no estabelecimento de relações entre essas figuras, assim o espaço no qual elas estão inseridas fica comprometido. 
Lima e Carvalho (2014, p. 84) acrescentam que as experiências do mundo físico, tais como "movimentação, manuseio, visualização e representação gráfica", envolvem a percepção sensorial e são fundamentais para o ensino e a aprendizagem da Geometria. Os autores ainda indicam que o "ensino inicial da Geometria deve partir da movimentação corporal, da visualização de objetos do mundo físico e de atividades que envolvam representações gráfica - desenhos e outras imagens gráficas - desses objetos" (LIMA; CARVALHO, p.84).

Kaleff (1994) constatou, em sua pesquisa, que apesar de nosso mundo ser tridimensional, a maior parte do material didático que as escolas apresentavam às crianças para ensinar Geometria à época era bidimensional. Ela exemplifica essa condição mencionando os desenhos trabalhados sobre superfícies planas, como no papel ou na lousa. Em pesquisa mais recente, Vasconcellos (2008) encontra situação semelhante no trabalho em sala de aula, que na visão do autor, continua a valorizar "a repetição, a classificação e a memorização das nomenclaturas das figuras planas, relegando a um momento posterior à exploração e a manipulação dos sólidos geométricos" (VASCONCELLOS, 2008, p. 83).

Percebe-se que apesar dos conceitos geométricos serem uma parte importante do currículo, pois "por meio deles, o aluno desenvolve um tipo especial de pensamento que the permite compreender, descrever e representar, de forma organizada, o mundo em que vive" (BRASIL, 1997, p. 39), muitos professores que ministram aulas de matemática nos anos iniciais, ainda encontram grandes dificuldades com a linguagem matemática a ser utilizada com relação a esse conteúdo.

Quando falamos sobre a geometria não podemos nos restringir apenas ao aspecto formal da linguagem geométrica, pois ela como linguagem utilizada para compreender, descrever e representar o mundo no qual vivemos, só deixará de ser vista como uma linguagem simbólica e indecifrável a partir do momento em que o professor conseguir estabelecer uma relação dessa linguagem com os contextos nos quais ela faz-se presente. Para tanto, as atividades organizadas para o trabalho em sala de aula devem garantir essa importante articulação.

Em nossa pesquisa, quando nos referimos à linguagem matemática que se ensina em um curso de Pedagogia, especificamente no conteúdo de Geometria, queremos olhar a utilização correta das nomenclaturas das figuras planas e sólidos geométricos, bem como, a articulação dessa nomenclatura na apresentação de conceitos, nos exemplos utilizados, na apresentação de atividades, e, na articulação dessa linguagem com a língua materna por parte da professora formadora.

\section{Metodologia}

Para a realização da pesquisa, adotamos como procedimento metodológico uma abordagem qualitativa, pois entendemos que esse tipo de abordagem vem ao encontro da solução de nossa questão de investigação. Compartilhamos, ainda, com Bogdan e Biklen (1994), ao entender que essa abordagem "exige que o mundo seja examinado com a ideia de que nada é trivial, que tudo tem potencial para construir uma pista que nos permita estabelecer uma compreensão mais esclarecedora do nosso objeto de estudo" (BOGDAN; BIKLEN, 1994 p. 49).

Visto que o estudo investiga a atuação de uma professora formadora em um curso de Pedagogia de uma Universidade Pública Estadual do Paraná, nossa pesquisa configura-se como um estudo de caso, que tem como fonte principal o campo de estudo que foi investigado 
(BOGDAN; BIKLEN, 1994). Por conseguinte, Stake (1995) nominando este tipo de estudo como estudo de caso instrumental, complementa que sua característica é responder "como" e "por quê" certos fenômenos acontecem em sala de aula.

Dessa forma, esta pesquisa segue etapas metodológicas, as quais foram submetidas ao Comitê Permanente de Ética em Pesquisa com Seres Humanos (COPEP - UEM) e aprovadas pelo parecer Número: 3.794.224. CAAE: 23582419.6.0000.0104.

Como procedimento para selecionar a Universidade Pública do Estado do Paraná onde realizamos nossa pesquisa, adotamos como critério que essa universidade fosse próxima ao pesquisador. Definimos ainda, que o professor formador que ministrava a disciplina de Metodologia de Ensino de Matemática no curso de Pedagogia não tivesse formação específica na área de Matemática, pois entendemos que aquele cuja formação é específica, certamente dominaria a linguagem matemática a qual seria investigada.

Por proximidade, elencamos três instituições de Ensino Superior (IES). Após termos definido a possibilidade de realização desta pesquisa em uma dessas três instituições, fizemos um levantamento acerca da formação do professor que ministrava a disciplina de Metodologia de Ensino de Matemática. Descobrimos que, em duas das IES por nós escolhida, os professores responsáveis por essa disciplina no ano de 2019 eram professores formados em Matemática. Desse modo, uma única atendeu ambos os critérios estabelecidos para a escolha do participante.

Ao entrarmos em contato com $\mathrm{PF}^{4}$, explicamos os objetivos da pesquisa, para que a mesma tomasse ciência do Estudo que iria participar. Após ter tomado conhecimento, a PF prontamente aceitou colaborar com a pesquisa. Na época em que a pesquisa foi realizada, a PF participante era graduada em Pedagogia e Mestre Profissional em Ensino. Com 37 anos de idade, contava com 12 anos de experiência docente no Ensino Superior e experiência concomitante no Ensino Fundamental.

Adotamos como instrumentos de coleta: entrevista semiestruturada, notas de campo e gravações em áudio das aulas observadas. As aulas de Geometria na disciplina Metodologia do Ensino de Matemática, ocorreram no terceiro ano noturno do curso de Licenciatura em Pedagogia, pois segundo a matriz curricular vigente para a turma é nessa etapa do curso que a disciplina voltada para a Matemática ocorre. Tanto as observações, quanto à entrevista, ocorreram no final do segundo semestre de 2019.

O roteiro para realização da entrevista foi elaborado considerando três questões principais. Na primeira questão, nossos questionamentos à $\mathrm{PF}$ foram correlatos à trajetória de formação profissional para ministrar aulas em um curso de Pedagogia. Na segunda questão, investigamos que tipo de formação ela havia recebido para realizar o trabalho com a formação matemática dos futuros pedagogos e as possíveis dificuldades que ela apresentava para trabalhar com a Geometria. Por fim, na terceira questão investigamos o movimento da PF por formações complementares que viessem a aprimorar sua prática docente.

No segundo momento da coleta de dados, utilizamos como instrumento às notas de campo, com o intuito de analisar os saberes docentes da professora formadora, a forma que a Linguagem Matemática era utilizada nas aulas ao abordar o conteúdo e o ensino de Geometria, bem como, a relação que a PF estabelecia entre a linguagem matemática e a língua materna. Decidimos adotar as notas de campo, pois acreditávamos, assim como Bogdan e

\footnotetext{
${ }^{4}$ Informamos que a partir desse parágrafo quando nos referirmos à professora formadora participante de nossa pesquisa, utilizaremos a sigla PF.
} 
Biklen (1994, p. 150), que caso só contássemos com as gravações em áudio, correríamos o risco de perder "[...] a visão, os cheiros, as impressões e os comentários extra ditos antes ou depois".

Para que pudéssemos compreender nossa questão de investigação, buscamos organizar os dados em episódios. Utilizamos para definir episódio o conceito apresentado por Moura (2000, p. 64). Para o autor, um episódio pode ser definido como:

[...] frases escritas ou faladas que constituídos de cenas definidoras que o caracterizam. Esse se caracteriza por revelar uma interdependência entre os elementos de uma ação formadora. Assim, os episódios não são definidos a partir de um conjunto de ações lineares. Pode ser que uma afirmação de um elemento participante de uma atividade não tenha um impacto imediato sobre os outros sujeitos da coletividade. Este impacto poderá estar revelado em um outro momento em que o sujeito foi solicitado a utilizar-se de algum conhecimento para participar de uma ação no coletivo. (MOURA, 2000, p. 64).

Os episódios foram elaborados considerando o que Moura chama de 'elementos de uma ação formadora'. Desse modo, elaboramos os mesmos considerando as cenas que os constituem para que não corrêssemos o risco de que eles ficassem incompreensíveis ao leitor.

Ao definirmos as subcategorias do quadro síntese de cada episódio, propusemos uma organização que possibilitou retirar as informações que consideramos mais relevantes em nossas análises. Todavia, essas informações, não ocorreram na descrição dos episódios, de forma linear, pois respeitamos as atividades apresentadas pela PF e a interdependência dessas atividades com os saberes docentes por ela mobilizados.

Para cada episódio adotamos como categoria de análise a Linguagem Matemática que a professora formadora utiliza. Para olhar a utilização dessa linguagem, elencamos como subcategorias: a) a organização do conteúdo de Geometria que ela iria ministrar; b) a linguagem geométrica por ela utilizada ao enunciar esses conteúdos; c) a relação que ela estabelece ao apresentar esses conteúdos com a língua materna. Após elencarmos as subcategorias, verificamos quais elementos dos saberes docentes foram mobilizados em cada subcategoria.

Neste artigo, apresentamos um dos episódios de nossa pesquisa, no qual, a PF propôs atividades práticas e utilização de materiais manipuláveis como estratégia metodológica para o ensino de Geometria.

\section{Trabalhando a geometria com atividades práticas e materiais manipuláveis}

Nesse episódio, apresentamos algumas das atividades sugeridas pela PF para suas alunas quanto ao trabalho a ser realizado com a Geometria nos anos iniciais. A seguir, o Quadro 5 sintetiza as ações da PF para a realização desse trabalho. 
Quadro 5 - Categorização e síntese do trabalho de Geometria com atividades práticas e materiais manipuláveis

\begin{tabular}{|c|c|c|c|c|}
\hline \multicolumn{5}{|c|}{ EPISÓDIO 2: Trabalhando a Geometria com atividades práticas e materiais manipuláveis } \\
\hline Categoria & Subcategoria & Ação em sala de aula & $\begin{array}{l}\text { Elementos dos } \\
\text { saberes docentes }\end{array}$ & $\begin{array}{c}\text { Saberes } \\
\text { constituídos } \\
\text { pelos elementos }\end{array}$ \\
\hline \multirow[t]{2}{*}{$\begin{array}{l}\text { Linguagem } \\
\text { Matemática } \\
\text { utilizada nas } \\
\text { aulas de } \\
\text { Geometria }\end{array}$} & $\begin{array}{l}\text { Organização da } \\
\text { sequência das aulas }\end{array}$ & $\begin{array}{l}\text { - Valoriza a realização } \\
\text { de atividades práticas. } \\
\text { - Valoriza a utilização } \\
\text { de materiais } \\
\text { manipuláveis como } \\
\text { objetos de sucata. } \\
\text { - Toma como ponto de } \\
\text { partida o mundo real } \\
\text { das crianças. } \\
\text { - Critica o modelo } \\
\text { tradicional de ensino. }\end{array}$ & $\begin{array}{l}\text { - Relação teoria e } \\
\text { prática. } \\
\text { - Utilização de } \\
\text { materiais } \\
\text { manipuláveis para } \\
\text { ensinar } \\
\text { matemática. } \\
\text { - Valorização da } \\
\text { realidade das } \\
\text { crianças como } \\
\text { ponto de partida } \\
\text { para o ensino de } \\
\text { conteúdos. } \\
\text { - Realização de } \\
\text { atividades com } \\
\text { sucatas de } \\
\text { embalagens } \\
\text { presentes na vida } \\
\text { das crianças para } \\
\text { não se restringir a } \\
\text { aulas expositivas de } \\
\text { demonstrações } \\
\text { matemáticas. }\end{array}$ & $\begin{array}{l}\text { - Saber de } \\
\text { formação } \\
\text { profissional do } \\
\text { Pedagogo. } \\
\text { - Saber de } \\
\text { formação } \\
\text { profissional do } \\
\text { Pedagogo e } \\
\text { saber } \\
\text { experiencial. } \\
\text { - Saber de } \\
\text { formação } \\
\text { profissional do } \\
\text { Pedagogo. } \\
\text { - Saber de } \\
\text { formação } \\
\text { profissional do } \\
\text { Pedagogo. }\end{array}$ \\
\hline & $\begin{array}{l}\text { Uso da linguagem } \\
\text { geométrica na aula }\end{array}$ & $\begin{array}{l}\text { - Cita elementos que } \\
\text { constituem a } \\
\text { linguagem geométrica, } \\
\text { tais como faces, } \\
\text { arestas e vértices e } \\
\text { planificação, mas não } \\
\text { utiliza as sucatas para } \\
\text { exemplificar e } \\
\text { demonstrar cada um } \\
\text { desses conceitos. }\end{array}$ & $\begin{array}{l}\text { - Conteúdo faces, } \\
\text { arestas, vértices. } \\
\text { - Conteúdo } \\
\text { Planificação das } \\
\text { faces de sólidos ou } \\
\text { modelos de sólidos } \\
\text { geométricos. (A } \\
\text { diferenciação entre } \\
\text { sólido e modelo de } \\
\text { sólido não foi } \\
\text { trabalhado pela } \\
\text { professora } \\
\text { formadora). }\end{array}$ & $\begin{array}{l}\text { - Saberes } \\
\text { disciplinares e } \\
\text { curriculares de } \\
\text { matemática. } \\
\text { - Saberes } \\
\text { disciplinares e } \\
\text { curriculares de } \\
\text { matemática. }\end{array}$ \\
\hline
\end{tabular}




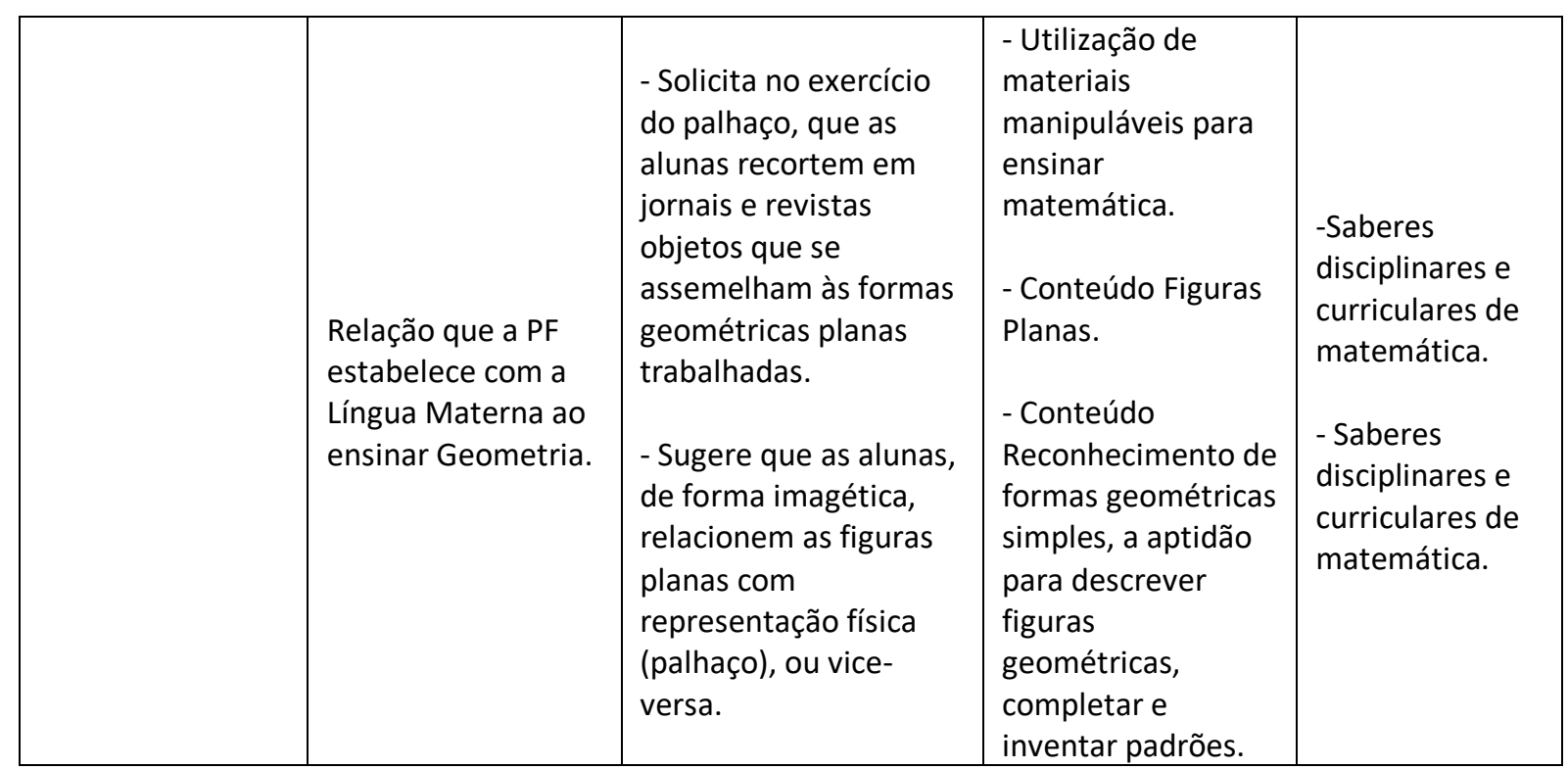

Fonte: o autor.

Como apresentado no Episódio 1, a PF relata a importância da relação teoria e prática para o trabalho com a Geometria e, criticando o ensino tradicional, sugere a importância de se tomar como ponto de partida para realização desse trabalho o mundo real da criança.

Novamente, nesse Episódio, a professora enfatiza a importância dos elementos que constituem os saberes de formação profissional discutidos em cursos de Pedagogia, que são a relação teoria e prática e críticas as posturas tradicionais de ensino. Além desses ela apresenta um elemento novo, que é tomar, como ponto de partida, nas práticas de sala de aula, o mundo real da criança.

Para discutir e compreender a defesa realizada pela PF quanto à utilização de atividades práticas e materiais manipuláveis, retomemos brevemente alguns aspectos históricos. $\mathrm{O}$ ensino da matemática na Tendência Formalista Clássica começou a perder força com o advento do movimento escolanovista desencadeado por John Dewey que surge no Brasil a partir da década de 20 (FIORENTINI, 1995). De lá para cá, fortes críticas, assim como as apresentadas pela PF, foram feitas ao ensino tradicional e, até hoje, apesar de novas tendências pedagógicas, tais como a Tendência Formalista Moderna, a Tendência Tecnicista, a Tendência Construtivista e a Socioetmocultural (FIORENTINI, 1995) terem influenciado as práticas dos professores no ensino de matemática, o ideário, tanto da escola tradicional quanto dos métodos ativos escolanovistas, ainda marcam forte presença nas escolas.

Para a PF, a ruptura com o ensino tradicional pode ser realizada, e sugere na fala a seguir como realizá-la:

Professora formadora: Nós não vamos ficar trabalhando com arestas, faces e vértices. Enfim, com classificações. Mas precisamos trabalhar a partir de modelos concretos do mundo real das crianças, de modo que elas possam formar os conceitos essenciais da Geometria. Vamos trabalhar com a manipulação de materiais para fazer as crianças refletir, por meio de atividades, a construção dos conceitos geométricos.

(Fala PF, 2019, grifo nosso).

Percebemos na fala da PF que a atividade pedagógica em matemática não deve ter um formato pautado estritamente na matemática formal. Ela sugere a utilização de materiais que estejam relacionados ao mudo real das crianças. Logo, nos parece que a utilização de materiais 
concretos no trabalho com a matemática é uma característica adquirida pela PF no decorrer de sua formação profissional. Quando a entrevistamos, ela já havia demonstrado essa preocupação quando indagada sobre o que não poderia faltar em uma aula de Geometria para os futuros professores que atuarão nos anos iniciais. Em resposta a essa pergunta, a PF afirma:

Professora formadora: é muito importante nas aulas de Geometria utilizar materiais manipuláveis. Eu acho que esses materiais facilitam a compreensão dos alunos. Por exemplo: quando estamos mostrando as faces, arestas e vértices, nos materiais, é diferente de mostrar no desenho. Na minha opinião, manipular os objetos permite que o aluno dos anos iniciais tenha uma compreensão maior da Geometria".

(Fala PF, 2019).

A fala inicial da PF em sala de aula parece desvalorizar o trabalho com conceitos como faces, arestas e vértices. Todavia, no áudio correlato à sua entrevista, foi possível compreender que ela valoriza o trabalho com tais conceitos relacionando-os com objetos do mundo real como os materiais manipuláveis. Nesse sentido, Borges (2009) corrobora a ideia de que o professor é responsável por determinar o momento certo para passar da linguagem intuitiva para a linguagem formal, e acrescenta que "a Geometria nos anos iniciais se caracteriza primordialmente como linguagem que parte do concreto para o simbólico" (BORGES, 2009, p.6). Por conseguinte, compartilhamos com o autor que as crianças devem "manipular, construir, observar, compor, decompor e agrupar por semelhanças ou diferenças" (BORGES, 2009, p.6), descobrindo relações. Cabe ao professor, atuar como mediador desse processo, assim como o fez a PF.

A PF, para reforçar sua explanação quanto à importância da utilização dos materiais manipuláveis, apresenta uma caixinha de creme dental como exemplo de objeto do mundo real que podem ser utilizados para trabalhar a Geometria. Com a caixinha na mão, a PF pergunta às alunas: "será que as crianças conhecem essa caixa?" (PF, 2019). Na sequência, apresenta rolos de papel higiênico e uma caixa de remédio.

A PF, continuando sua explicação sobre a utilização dos materiais manipuláveis que estão relacionados com o mundo real e podem ser trabalhados com as crianças, apresenta outros objetos como: caixa de lápis de cor, caixa de remédio, além de outras sucatas. Acrescenta que nem sempre na escola são encontrados materiais como os sólidos geométricos, porém afirma que essa condição e o fato do professor não poder adquirir materiais com seus próprios recursos financeiros, não justifica uma aula sem materiais, já que a sucata pode ser solicitada aos alunos, que trarão os materiais para a escola. A PF complementa que essas sucatas podem ser utilizadas para a realização de atividades como planificação para obter, por exemplo, figuras planas.

Observamos que a PF apresenta possibilidades de trabalho com materiais manipuláveis, mas não busca enfocar os conteúdos que podem ser trabalhados a partir dessa utilização. Talvez isso ocorra pelas fragilidades indicadas por ela em relação aos "saberes disciplinares" (TARDIF, 2002) de Matemática em seu processo de formação. Nas suas falas, percebemos, por exemplo, a citação de conceitos importantes relacionados à linguagem geométrica, tais como faces, arestas, vértices, planificação, mas não propõe atividades para que as suas alunas, futuras professoras, se apropriem desses conceitos para poder ensinar.

Outro conteúdo que poderia ter sido explorado é o conceito de sólido geométrico, a partir das sucatas utilizadas. Seria oportuno ter mencionado que as embalagens representam modelos de sólidos, já que "um sólido é, basicamente, uma porção do espaço limitada por 
superfície planas ou curvas. É, portanto, uma figura tridimensional compacta (não oca)" (CARNEIRO SOARES; VIANA, 1990, p. 19). Nesse sentido, compartilhamos com as contribuições de Moura (2010), pois acreditamos, assim como o autor, que os professores deveriam estar mais preocupados com os fenômenos menos aparentes da ação pedagógica que, talvez, estejam na "interdependência entre o conteúdo de ensino, as ações educativas e os sujeitos que fazem parte da atividade educativa" (MOURA, 2010, p. 207). Todavia, nesse episódio, percebemos que a ênfase dada pela professora foi em relação à falta de materiais manipuláveis nas escolas e não aos conteúdos e ações metodológicas que poderiam ser trabalhadas para ensinar esses conteúdos com a utilização desses materiais. Este fato indica ainda o "saber experiencial" (TARDIF, 2002) da professora, adquirido por meio de sua atuação no Ensino Fundamental e Superior quanto à precariedade de recursos financeiros que as instituições apresentam para aquisição de materiais didáticos e pedagógicos.

Na continuidade de sua aula, a PF apresenta outra atividade que poderia, em sua opinião, contextualizar o ensino de Geometria com a realidade cotidiana. Desse modo, passaremos a apresentar a atividade na Figura 1, a seguir, assim como a professora o fez, para que possamos analisar a linguagem geométrica presente nessa atividade e quais relações ela possibilita com a língua materna, pois, assim como já havíamos citado em nosso capítulo de fundamentação, para Menezes (1999), a linguagem matemática só adquire significado a partir dos contextos de sua utilização.

Figura 1 - Atividade para trabalhar o reconhecimento de formas geométricas.

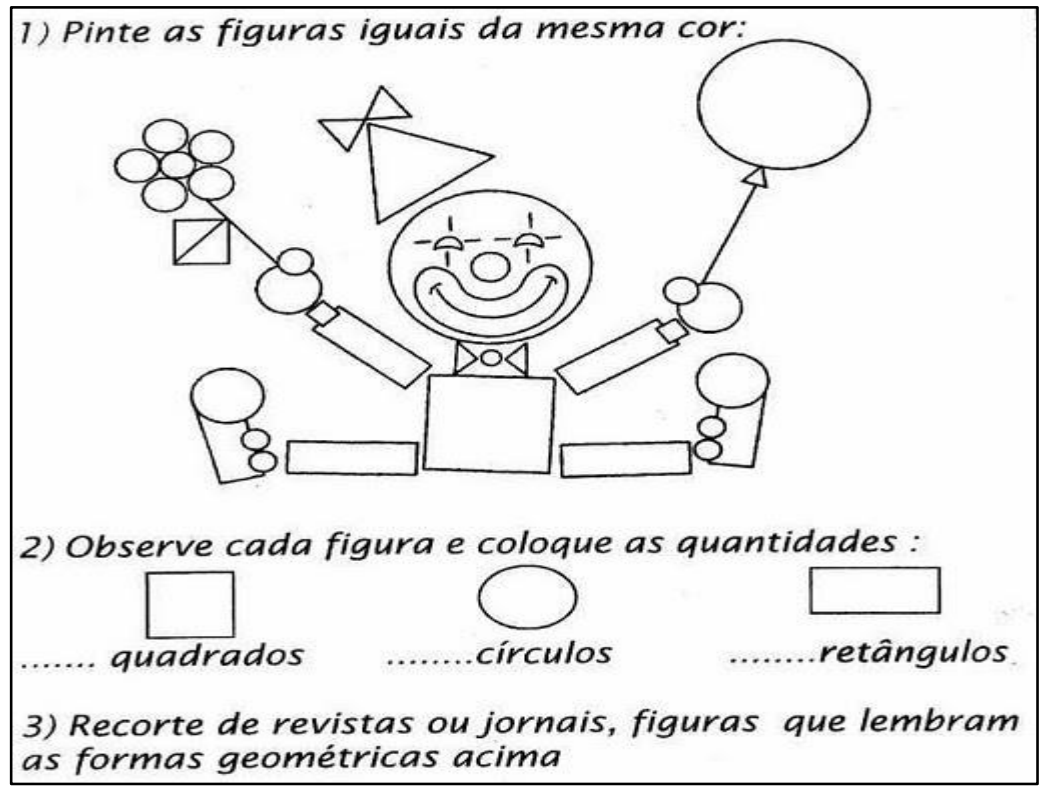

Fonte: a pesquisa.

A PF apresentou a atividade representada pela Figura 2, mostrada anteriormente, para trabalhar o "reconhecimento de formas geométricas simples, e a aptidão para descrever figuras geométricas, completar e inventar padrões" (PF, 2019). Segundo ela, esses conteúdos são elementos que constituem os saberes disciplinares de matemática no Ensino Fundamental, pois são conteúdos que constam no currículo dessa disciplina.

Como podemos observar na Figura 2, as atividades vêm ao encontro do saber curricular por ela proposto. Ela apresenta a figura de um palhaço cujos desenhos que $o$ 
constituem são formas geométricas simples, e ao solicitar, no enunciado 1, que os alunos pintem as figuras iguais, percebemos sua intenção de que os mesmos consigam identificar os padrões de cada forma. Já no enunciado 2 , a atividade exige de quem os resolve, após terem identificado os padrões de similaridade, quantificar as formas iguais. No enunciado 2, a atividade parece buscar uma relação entre a Geometria e a aritmética, em relação à quantificação das figuras iguais, mas também reforça padrões de similaridade.

No enunciado 3, com o intuito de estabelecer uma relação com a realidade, a atividade proposta pela PF permite àqueles que a executam perceber que imagens de objetos cotidianos podem ser representadas e apresentar similaridade com as formas geométricas planas.

Utilizando os estudos de Lima e Carvalho (2014) quanto às representações em Geometria, eles acrescentam que o sentido da visão cumpre um papel na formação do pensamento geométrico que está relacionado a duas capacidades estreitamente interdependentes, quais sejam: "a capacidade de ver objetos (físicos ou gráficos), o movimento e o espaço físico e de gerar imagens mentais" e a capacidade de "tornar visíveis nossas ideias e imagens mentais, por meio de objetos físicos ou de representações gráficas" (LIMA; CARVALHO, 2014, p. 93). Diante das considerações dos autores, a atividade do palhaço, exibida pela $P F$, pode ser um exemplo de uma atividade que desenvolve essas duas capacidades, pois é uma prática, que, no enunciado 3, exige a percepção por parte dos alunos de uma "representação gráfica de objetos espaciais por meio de desenhos ou de outras imagens gráficas que se realizam em uma superfície plana" (LIMA; CARVALHO, 2014, p. 93). Além disso, o enunciado 3, ao ser executado, permite que os alunos gerem imagens mentais a partir da representação gráfica.

\section{Considerações finais}

Propusemos, como objetivo desta dissertação, investigar os saberes docentes que são colocados em ação na prática pedagógica quando a PF articula linguagem matemática e língua materna no ensino de Geometria em uma disciplina de Metodologia de Ensino de Matemática. O contexto por nós escolhido, e que apresentava as condições objetivas para a realização desta pesquisa, foi um curso de Pedagogia de uma universidade pública do estado do Paraná.

Os saberes docentes revelados na docência dos conteúdos de Geometria foram, ainda, observados levando-se em conta a articulação que a PF realizava entre a linguagem matemática e língua materna no decorrer de suas aulas, pois concluímos, a partir da nossa pesquisa, que o ensino de matemática não pode ser considerado apenas em seu aspecto formal, mas também como uma formação cultural. Nesse sentido, acreditamos que a forma como a PF apresentava os conteúdos e utilizava a língua materna para relacioná-los com a realidade possibilitava, ou não, a formação cultural de seus alunos.

É importante lembrar que, como tratava-se de uma PF em um curso de formação inicial, e o objetivo de sua disciplina era a formação de futuros professores dos anos iniciais que viriam a ensinar matemática, nosso olhar esteve embebido pelo conhecimento do conteúdo por parte da PF e da metodologia por ela proposta para o ensino desse conteúdo, dado que os estudos teóricos e as análises realizadas nesta pesquisa nos permitiram afirmar que para ensinar Geometria a linguagem matemática utilizada deve ser apresentada de maneira correta nas ações de ensino. 
Os dados nos trazem, como elementos de seus saberes docentes, o fato de que havia uma preocupação por parte da PF com a forma de organizar as suas aulas de modo a fugir das estratégias tradicionais de ensino dos conteúdos de Geometria, pois, segundo sua crença, a depender da forma de organização da aula, ela seria ou não fonte motivacional de aprendizagem. Outro elemento mobilizado pela PF, e observado em campo, foi seu esforço quanto à apresentação de metodologias de ensino que utilizassem materiais manipuláveis para desvencilhar-se do ensino tradicional e estabelecer uma relação entre teoria e prática, bem como valorizar situações vinculadas à realidade. Por meio de slides, a PF apresentava algumas contribuições de autores relativas à Geometria e alguns conceitos matemáticos. Essa forma de trabalhar e organizar suas aulas, era por ela justificada devido à importância da relação teoria e prática.

Ainda com relação às estratégias tradicionais de ensino, observamos que a PF, apesar de tentar fugir das mesmas e valorizar a utilização de materiais manipuláveis, em momentos importantes da aula, cuja utilização de materiais manipuláveis seria fundamental, transmitiu exemplos por meio de preleções ou de desenvolvimentos teóricos utilizando imagens em Power Point para, depois, apresentar a atividade prática às alunas. Esse movimento demonstra que o discurso de crítica ao ensino tradicional apresentado pela professora formadora nem sempre é utilizado em suas ações de ensino. Isso, segundo nossas constatações, ocorre em razão da forte influência de um ensino tradicional na história de formação de professores em serviço e futuros professores, o qual é centrado na memorização, na repetição, e em abordagens metodológicas empíricas. $O$ ensino tradicional, em relação aos conteúdos matemáticos, parece limitar o processo de pensamento daqueles que foram formados por essa tendência pedagógica.

No tocante à atividade do palhaço, percebemos que a PF conseguiu promover uma relação das figuras planas que compõem o desenho utilizado. Ou seja, as alunas puderam, a partir das figuras planas, imaginar uma composição que representa algo vinculado à realidade. Além disso, por meio da representação, esse tipo de atividade permite a percepção de padrões geométricos e estimula a imaginação. Com isso, é no campo da imaginação que poderá estar situada a relação da linguagem geométrica à língua materna.

Contudo, as dificuldades apresentadas pela PF em relação aos elementos que constituem os saberes pedagógicos e os saberes matemáticos por ela mobilizados em sua atividade de ensino, interferiram na qualidade da organização e proposição de metodologias e conteúdos necessários à formação das futuras pedagogas. Assim, a PF não conseguiu estabelecer na formação inicial de suas alunas uma relação entre a linguagem matemática e a língua materna que permitisse uma compreensão significativa dos conteúdos de geometria trabalhados na disciplina de Metodologia de Ensino de Matemática.

O abandono desse ensino, como indicado nas pesquisas, e ainda hoje, traz consequências no campo da formação de professores que irão ensinar Geometria, pois não possuindo o domínio dos conteúdos específicos, não saberão expressar-se por meio de uma linguagem matemática, e também não conseguirão estabelecer as relações necessárias desse ensino com os contextos da língua materna para que seja alcançada a formação pretendida.

Por fim, uma articulação de qualidade por parte da PF quanto aos saberes da docência, tais como os saberes disciplinares, curriculares, de formação profissional e experienciais, ao ensinar Geometria, só poderá ser garantida de duas formas: primeiro se o PF tiver formação específica em matemática, e segundo, no caso do Pedagogo, que sejam propostas formações em serviço que considerem as necessidades formativas desses profissionais em áreas 
específicas como a Matemática. Ao tomar, como ponto de partida, as necessidades formativas do PF quanto ao conteúdo específico da Geometria será possível, no movimento de formação, promover a articulação entre a linguagem matemática e a língua materna, com o intuito de estabelecer a tão pretendida relação teoria e prática defendida por nós e pela PF.

\section{Referências}

BOGDAN, R. C.; BIKLEN, S. K. Investigação qualitativa em educação. Tradução de Maria João Álvares, Sara Bahia dos Santos e Telmo Mourinho Baptista. Porto - Portugal: Porto, 1994. 336 p.

BORGES, M. A. Geometria nos anos iniciais do ensino fundamental: novas perspectivas. Anais dos Congressos de Pedagogia, n. 25, 2009.

BROITMAN, C.; ITZCOVICH, H. Geometria nas séries iniciais do ensino fundamental: problemas de seu ensino, problemas para seu ensino. In: PANIZZA, M. et al. Ensinar matemática na educação infantil e nas séries iniciais: análise e propostas. Porto Alegre: Artmed, v. 2, 2006. Cap. 8, p. 169-186.

CURI, E. Formação de professores polivalentes: uma análise de conhecimentos para ensinar Matemática e de crenças e atitudes que interferem na constituição desses conhecimentos. PUC/SP, 2004.

CURI, E. A matemática e os professores dos anos iniciais: uma análise dos conhecimentos para ensinar matemática e das crenças e atitudes que interferem na constituição desses conhecimentos. Musa Editora, 2005.

CURI, E. A Formação Inicial de Professores para Ensinar Matemática: algumas reflexões, desafios e perspectivas. Revista de Matemática, Ensino e Cultura, Natal, v. 6, n. 9, p. 75-93, 2011.

DE ALMEIDA, M. B.; DE LIMA, M. G. Formação inicial de professores e o curso de pedagogia: reflexões sobre a formação matemática. Ciência \& Educação (Bauru), v. 18, n. 2, p. 451-468, 2012

EDWARDS, V. Os sujeitos no universo da escola. São Paulo: Ática, 1997.

FIORENTINI, D. Alguns modos de ver e conceber o ensino da matemática no Brasil. Zetetiké, v. 3, n. 1, 1995.

FIORENTINI, D. Formação de professores que ensinam matemática: um balanço de 25 anos de pesquisa brasileira. 2002

FURLANETTO, F. R. O movimento de mudança de sentido pessoal na formação inicial do professor. 2013. Tese de Doutorado. Universidade de São Paulo.

KALEFF, A. M. Tomando o ensino de Geometria em nossas mãos. Educação Matemática em Revista, p. 19-25, 1994.

LIMA, P. F.; CARVALHO, J. B. P. A Geometria escolar hoje: conversas com o professor que ensina matemática. In: SILVA, M.C.L. da; VALENTE, W. R. A Geometria nos primeiros anos escolares: história e perspectivas atuais. 1ed. Campinas, SP: Papirus, 2014. Cap. 4, 83-128.

LORENZATO, S. Por que não ensinar Geometria?, Educação em Revista -Sociedade Brasileira de Educação Matemática - SBM, ano 3, n. 4, p. 4 -13, $1^{\circ}$ sem. 1995. 
MENEZES, L. Matemática, linguagem e comunicação. Millenium, 2000.

MORETTI, M. T.; HILLESHEIM, S. F. Linguagem natural e formal na semiosfera da aprendizagem Matemática: o caso da Geometria para a formação do Pedagogo. EM TEIA - Revista de Educação Matemática e Tecnológica Iberoamericana, vol. 9 - n. 1, 2018

MOURA, M. O. et al. Atividade orientadora de ensino: unidade entre ensino e aprendizagem. Revista Diálogo Educacional, v. 10, n. 29, p. 205-229, 2010.

MOURA, M. O. O educador matemático na coletividade de formação: uma experiência com a escola pública. 2000. 131 p. Tese (Livre Docência em Metodologia de Ensino de Matemática). Faculdade de Educação, Universidade de São Paulo, São Paulo, 2000.

NACARATO, A. M. Educação continuada sob a perspectiva da pesquisa-ação: currículo em ação de um grupo de professoras ao tentar aprender ensinando Geometria. 2000. Tese de Doutorado. Tese (Doutorado). Campinas, SP: FE/Unicamp.

PAVANELLO, R. M. O abandono do ensino de Geometria: uma visão histórica. 1989. 196 f. 1989. Tese de Doutorado. Dissertação (Mestrado em Educação) -Faculdade de Educação, Universidade Estadual de Campinas, São Paulo.

PAVANELLO, R. M. O abandono do ensino da Geometria no Brasil: causas e consequências. Zetetiké, v. 1, n. 1, 1993.

PAVANELLO, R. M. et al. Formação de possibilidades cognitivas em noções geométricas. 1995.

PAVANELLO, R. M. Por que ensinar/aprender Geometria. VII Encontro Paulista de Educação Matemática, 2004.

PAVANELLO, R. M. A Geometria nas séries iniciais do ensino fundamental: contribuições da pesquisa para o trabalho escolar. Matemática nas séries iniciais do ensino fundamental: a pesquisa e a sala de aula. São Paulo: SBEM, p. 129-143, 2004.

PCN, Parâmetros Curriculares Nacionais. Matemática. Secretária de Educação Fundamental. Brasília: MEC/SEF, 1997.

STAKE, R. The art of case study research. Thousand Oaks, CA: Sage,1995.

TAQUES FILHO, L. S. Característica da formação matemática das futuras professoras das séries iniciais do ensino fundamental a partir de cursos pedagogia de Curitiba. Revista Intersaberes. Vol. 7 n. 14, p. 262 - 277, ago. - dez. 2012.

TARDIF, M. Saberes docentes e formação profissional. 2.ed. Petrópolis: Vozes, 2002. 325 p.

VASCONCELLOS, M. A diferenciação entre figuras geométricas não-planas e planas: o conhecimento dos alunos das séries iniciais do ensino fundamental e o ponto de vista dos professores. Zetetiké, v. 16, n. 2, 2008. 
VASCONCELOS, M. L. M. C. Contribuindo para a formação de professores universitários: relatos de experiências. In: MASETTO, Marcos (Org.). Docência na Universidade. Campinas, SP: Papirus, 1998. p. 77-94.

VIANNA, C. R.; SOARES, M. T. C. Caderno de Matemática para o professor. In: PARANÁ. Secretaria de Estado da Educação - Departamento de Ensino Supletivo. Abril, 1990.

ZORTÊA, G. A. P. Conhecimentos "de" e "sobre" Geometria de duas professoras iniciantes no contexto de um grupo colaborativo. 2018. Dissertação (Mestrado) - Universidade Estadual Paulista. Faculdade de Ciências, Bauru, 2018. 